\title{
Do differences in early hemodynamic performance of current generation biologic aortic valves predict outcomes 1 year following surgery?
}

\author{
Nassir M. Thalji, MBChB, ${ }^{a}$ Rakesh M. Suri, MD, DPhil, ${ }^{a}$ Hector I. Michelena, MD, ${ }^{b}$ \\ Kevin L. Greason, MD, ${ }^{\mathrm{a}}$ Joseph A. Dearani, MD, ${ }^{\mathrm{a}}$ Richard C. Daly, MD, ${ }^{\mathrm{a}}$ Lyle D. Joyce, MD, ${ }^{\mathrm{a}}$ \\ John M. Stulak, MD, ${ }^{a}$ Harold M. Burkhart, MD, ${ }^{a}$ Zhuo Li, MSc, ${ }^{c}$ and Hartzell V. Schaff, MD ${ }^{a}$
}

Objective: Small early postoperative hemodynamic differences were noted in a randomized comparison of 3 current-generation bioprosthetic aortic valves. Whether these differences persist and influence clinical outcomes 1 year following implantation is unknown.

Methods: Three hundred adults with severe aortic stenosis undergoing valve replacement were randomized to receive the Epic (St Jude, St Paul, Minn) ( $n=99)$, Magna (Edwards LifeSciences Inc, Irvine, Calif) $(\mathrm{n}=100)$, or Mitroflow (Sorin Biomedica Spa, Saluggio, Italy) $(\mathrm{n}=101)$ bioprostheses. Hemodynamic valve performance was examined by echocardiography at 1 year, and clinical outcomes were assessed in 241 patients (79 Epic, 77 Magna, and 85 Mitroflow; $P=.437$ ).

Results: Mean age was $75 \pm 8$ years and 164 were men $(68 \%)$. Between dismissal and 1 year there were 9 deaths (3.7\%) (Epic: $3.7 \%$, Magna: $5.0 \%$, and Mitroflow: $2.3 \% ; P=.654), 6$ episodes of heart failure $(2.5 \%)$ (Epic: $1.3 \%$, Magna: $1.3 \%$, and Mitroflow: $5.8 \% ; P=.265$ ), 27 instances of atrial fibrillation/flutter (11.2\%) (Epic: $8.1 \%$, Magna: $11.0 \%$, and Mitroflow: $7.9 \% ; P=.577$ ) and no strokes/transient ischemic attacks. One-year echocardiography demonstrated small hemodynamic differences between Epic, Magna, and Mitroflow bioprostheses in mean gradient $(15.2 \pm 5.5,12.3 \pm 4.3$, and $16.2 \pm 5.7 \mathrm{~mm} \mathrm{Hg}$, respectively; $P<.001)$ and indexed aortic valve area $\left(0.93 \pm 0.28,1.04 \pm 0.28\right.$, and $0.96 \pm-0.26 \mathrm{~cm}^{2} / \mathrm{m}^{2}$, respectively; $P=.015)$. Several early trends persisted when stratifying data by echocardiographic annulus diameter, universal annulus size, and implant size, particularly with annular size $\geq 23 \mathrm{~mm}$. Overall left ventricular mass index regression between dismissal and 1 year was $-16.5 \pm 28.1 \mathrm{~g} / \mathrm{m}^{2}$, and was similar among groups $(P=.262)$. There were no aortic valve reoperations.

Conclusions: Despite midterm persistence of small hemodynamic differences amongst current-generation porcine and pericardial aortic valves, our prospective randomized comparison reveals that clinical outcomes and mass regression are equivalent between devices at 1 year. These encouraging trends must continue to be assessed during longitudinal follow-up. (J Thorac Cardiovasc Surg 2015;149:163-73)

\footnotetext{
From the Divisions of Cardiovascular Surgery ${ }^{\mathrm{a}}$ and Cardiovascular Diseases, ${ }^{\mathrm{b}}$ and Department of Biomedical Statistics and Informatics, ${ }^{\mathrm{c}}$ Mayo Clinic, Rochester, Minn.

Supported by St. Jude Medical, Edwards Lifesciences, and Sorin Group.

Disclosures: The Division of Cardiovascular Surgery at the Mayo Clinic reports research relationships with Edwards LifeSciences, Medtronic, and St Jude Medical. R.M.S. is the national principal investigator for the Food and Drug Administration trial of the Sorin Perceval valve, a member of the steering committee of the St Jude Portico trial, a member of the clinical selection committee for the $\mathrm{Ab}$ bott Coapt trial, and site principal investigator for the Edwards Partner II trial. R.C.D. serves on the advisory board of Neochord, Inc. None of the disclosures pertain to the current investigation. The other authors have nothing to disclose with regard to commercial support.

Read at the 94th Annual Meeting of The American Association for Thoracic Surgery, Toronto, Ontario, Canada, April 26-30, 2014.

Received for publication April 28, 2014; revisions received Aug 25, 2014; accepted for publication Sept 10, 2014; available ahead of print Oct 16, 2014.

Address for reprints: Rakesh M. Suri, MD, DPhil, Division of Cardiovascular Surgery, Mayo Clinic College of Medicine, 200 First St, SW, Rochester, MN (E-mail: suri.rakesh@mayo.edu).

$0022-5223 / \$ 36.00$

Copyright (c) 2015 by The American Association for Thoracic Surgery

http://dx.doi.org/10.1016/j.jtcvs.2014.09.027
}

See related commentary on pages 173-4.

Supplemental material is available online.

In elderly patients undergoing surgical aortic valve replacement (AVR), biologic prosthetic valves may be preferred over mechanical prostheses because they overcome the need for long-term anticoagulation therapy and diminish corresponding lifestyle restrictions. However, among patients in whom a bioprosthetic implant is deemed appropriate, equipoise persists regarding merits of porcine versus bovine pericardial aortic implants. ${ }^{1,2}$ Further, and despite assertions of improved performance 


\section{Abbreviations and Acronyms \\ AVA $=$ aortic valve area \\ $\mathrm{AVAi}=$ aortic valve area index \\ $\mathrm{AVR}=$ aortic valve replacement \\ $\mathrm{LV}=$ left ventricular}

of third-generation aortic valve prostheses, ${ }^{3-8}$ it remains uncertain as to whether there are differences in the hemodynamic profile and long-term durability of valves with different constructions.

In a prospective randomized study of 300 patients with severe aortic stenosis presenting for surgical AVR, we previously compared the immediate postoperative performance of 3 commonly used current generation biologic aortic valve prostheses: the Epic porcine valve (St Jude Medical, St Paul, Minn), the Magna bovine pericardial valve (Edwards LifeSciences, Irvine, Calif), and the Mitroflow bovine pericardial valve (Sorin Biomedical Spa, Saluggia, Italy). ${ }^{9}$ Although we identified small but consistent early postoperative hemodynamic differences between the 3 groups, whether such differences persist and their effect on midterm outcomes 1 year following dismissal from hospital are unknown. We prospectively follow these patients and compare herein hemodynamic performance, prosthetic valve durability, and clinical outcomes at 1 year following index aortic valve implantation.

\section{METHODS}

This prospective randomized study was approved by the Mayo Clinic Institutional Review Board.

\section{Study Subjects}

As previously detailed, ${ }^{9} 300$ consecutive patients referred for biologic AVR between August 2009 and November 2011 were considered for enrollment in this study. Exclusion criteria included age younger than 18 years, emergency surgery, prior prosthetic heart valve implantation in any location, prior aortic valve procedure, prior aortic root replacement, concomitant replacement of nonaortic valves, active endocarditis, and severe aortic valve insufficiency. Patients with a history of healed aortic valve endocarditis and those undergoing concomitant procedures (ie, coronary artery bypass grafting and valve repair) remained eligible for inclusion.

Herein we examine outcomes of 241 of the $300(80 \%)$ patients who were available for follow-up at 1-year post-AVR. A patient flow diagram is outlined in Figure 1. All patients provided informed consent and identified willingness to comply with study protocols.

\footnotetext{
AVR

Techniques for randomization and valve replacement have been previously detailed. $^{9}$ Using statistical software (SAS version 9.2, SAS Institute, Inc, Cary, NC) the statistician generated randomization numbers printed on cards and sealed in envelopes. All patients underwent standard cardiopulmonary bypass and cold-blood cardioplegic arrest. Following aortotomy, excision of the native valve, and aortic annular debridement,
}

the aortic annulus was measured using a calibrated universal sizer $(19,21$, $23,25,27$, and $29 \mathrm{~mm}$ ). Thereafter, envelopes were opened and randomization groups identified: Epic, Magna, or Mitroflow. Using prosthesis-specific sizers provided by the manufacturers, the aortic annulus was again measured. Surgeons made a concerted effort to implant the largest possible prosthesis. Biologic prostheses were implanted using noneverting pledgeted stitches.

The Epic valve is a triple-composite bioprosthetic valve constructed from select porcine aortic valve cusps matched for optimal leaflet coaptation. Following fixation, tissue is mounted on a polyester-covered flexible copolymer stent. The Magna valve is manufactured from glutaraldehyde-fixed bovine pericardium mounted on a 3-pronged polyester Elgiloy stent. The Mitroflow valve is a stented bioprosthetic valve constructed from glutaraldehyde-fixed bovine pericardium sutured on a flexible, polyester cloth-covered acetyl homopolymer stent. The thickness of pericardial tissue was matched to the diameter of the stent in these valves. All prosthetic valves used in this study were between sizes 19 and 27.

\section{Data Collection}

Study participants returned for assessment at 1 year following surgery. The primary end point was hemodynamic performance of the biologic prosthetic valve at 1-year post-AVR, an evaluation of which is detailed below (see Echocardiography). Secondary outcomes were clinical events at 1 -year follow-up. Specifically, patients were examined and evaluated for incidence of stroke, transient ischemic attack, hospital admission for congestive heart failure, development of atrial fibrillation/ flutter, and reoperative AVR. Mortality data following hospital discharge was obtained by review of medical records, the electronic Accurint database (www.Accurint.com), contact with next of kin, and death certificates.

\section{Echocardiography}

In addition to preoperative and intraoperative echocardiography assessment, patients underwent further comprehensive 2-dimensional and Doppler echocardiographic evaluation using state-of-the-art technology before hospital dismissal, and-among patients with midterm follow-up data-at 1 year following AVR.

As previously detailed, ${ }^{9}$ left ventricular (LV) ejection fraction was evaluated by 2 -dimensional echocardiography in the LV short-axis view, and using a modified technique detailed by Quinones and colleagues, ${ }^{10}$ or by visual estimate. ${ }^{11}$ In alignment with best practice, continuous-wave and pulsed Doppler measurements were recorded ${ }^{12}$ taking an average of 3 beats. In patients with atrial fibrillation an average of 5 to 10 beats was taken. LV outflow tract diameter was measured in the parasternal long-axis view during mid-systole, and in the native aortic valve by measuring the inner edges from where the anterior cusp meets the ventricular anteroseptum, to where the posterior cusp meets the anterior mitral valve leaflet. In prosthetic aortic valves, the measurement was from the outer edge of the anterior sewing ring to the outer edge of the posterior sewing ring. Mean transvalvular aortic gradient, peak velocity, and aortic valve time-velocity integral were automatically calculated by echocardiographic software. Multiple echocardiographic windows were explored to obtain the highest continuous-wave Doppler envelope of the aortic valve. The aortic valve area (AVA) was automatically calculated by the continuity equation, and indexed to body surface area (AVAi). Stroke work loss was reported as a percent and calculated using a previously detailed formula. ${ }^{13}$ Finally, LV mass was calculated in accordance with the previously validated ${ }^{13-15}$ American Society of Echocardiography formula, ${ }^{16}$ and using 2-dimensional or M-mode measurements, and indexed to body surface area.

One cardiologist specializing in echocardiography imaging (H.I.M.) supervised uniform echocardiography data collected and reported in this study. 


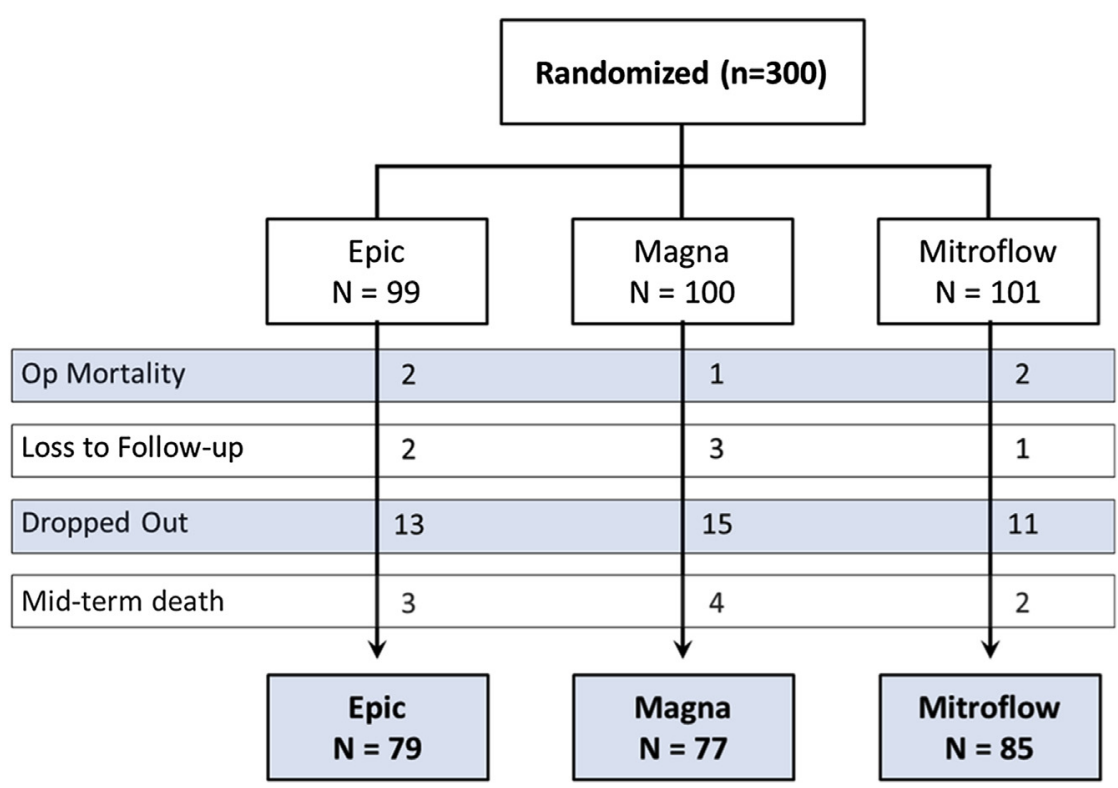

FIGURE 1. Flow diagram of patient flow from enrollment to 1-year follow-up. Epic (St Jude, St Paul, Minn), Magna (Edwards LifeSciences Inc, Irvine, Calif), and Mitroflow (Sorin Biomedica Spa, Saluggio, Italy). Op, Operative.

\section{Statistical Analysis}

Continuous variables were summarized as means \pm standard deviations or medians (interquartile range) as appropriate, and compared between groups using 1-way analysis of variance or Kruskal-Wallis test where appropriate. Categorical variables were summarized as counts (percentages) and compared using $\mathrm{R}$ by $\mathrm{C}$ contingency tables or Fisher exact test. To evaluate changes in echocardiographic measurements within individual patients, paired $t$ tests or Wilcoxon tests were used where appropriate. The Kaplan-Meier technique was used to evaluate survival at 1 year, with patient censoring at dropout or loss to follow-up. Univariate and multivariate linear regression analyses were used to identify predictors of LV mass index regression at 1-year follow-up. The SAS statistical software package (SAS Institute, Inc, Cary, NC) was used for all analyses.

At 1-year follow-up, echocardiographic data was available in 71 patients who received the Epic, 68 who received the Magna, and 78 who received the Mitroflow valve. When applying Bonferroni adjustment for multiple comparisons, and based on a common standard deviation of 5, an overall significance level of 0.05 and a minimum of 68 patients per group, our study has $80 \%$ power to detect a minimum difference in mean gradient of at least $2.8 \mathrm{~mm} \mathrm{Hg}$ between any 2 of the 3 groups.

In a secondary analysis, missing mean gradient, aortic valve area, aortic valve area index, and LV mass index values at 1 year (ie, in patients with clinical follow-up but missing echocardiographic data) were handled using multiple imputation analysis. Five multiple imputation data sets were created based on patient-specific values at preoperative and dismissal echocardiography, and nonmissing values at 1-year follow-up. The comparison of these variables between valve types was then carried out in each multiple imputation dataset using the above statistical methods. The results from all 5 sets of analyses were combined, and overall statistical references were generated using missing value analysis procedures using SAS. All statistical tests were 2 -sided. All statistical tests were 2 sided, and a $P$ value less than .05 -with Bonferroni adjustment for multiple comparisons-was considered statistically significant.

\section{RESULTS}

\section{Patient Characteristics}

Of 300 patients initially randomized, $241(80.3 \%)$ were evaluated at 1-year following AVR (Epic $=79$ out of 99 patients [79.8\%], Magna $=77$ out of 100 patients [77.0\%], and Mitroflow $=85$ out of 101 patients $[84.1 \%] ; P=.432)$. The mean age was $75 \pm 8$ years, and $68 \%$ (164) were men. The attrition of patients between randomization and 1-year follow-up is outlined in Figure 1. Table 1 depicts baseline characteristics and perioperative outcomes of patients with 1-year follow-up and stratified by implanted prosthesis. The 241 patients evaluated at 1 year were comparable across all baseline variables and perioperative outcomes, indicating preservation of initial randomization.

\section{One-Year Clinical Outcomes}

Between hospital dismissal and 1-year follow-up, there were a total of 9 deaths (3\%). One-year survival was comparable between patients receiving Epic (95.8\%), Magna (96.8\%), and Mitroflow $(97.9 \%)$ bioprosthetic valves $(P=.512)$. Six episodes of congestive heart failure (Epic, 1 [1.3\%], Magna, 1 [1.3\%], and Mitroflow, $4[4.7 \%] ; P=.265)$ and 27 instances of atrial fibrillation/ flutter (Epic, 8 [10.1\%], Magna, 11 [14.3\%], Mitroflow, $8[9.4 \%] ; P=.577)$ were documented, with no difference between groups (Table 2). There were no incidences of stroke/transient ischemic attack among all patients. Regarding prosthetic durability, reoperation was not required in any patients during the first year post-AVR.

\section{Hemodynamic Performance at 1 Year}

Comprehensive echocardiographic evaluation was available in $90 \%$ of patients (217 out of 241 ) with 1-year follow-up (Epic, 71 out of 79 [89.9\%], Magna, 68 out of 77 [88.3\%], and Mitroflow, 78 out of 85 [91.8\%]; 
TABLE 1. Perioperative characteristics of patients with 1-year follow-up following valve replacement with 1 of 3 current-generation bioprosthetic aortic valves

\begin{tabular}{|c|c|c|c|c|}
\hline Variable & Epic* $(\mathbf{n}=79)$ & $\operatorname{Magna} \nmid(\mathbf{n}=77)$ & Mitroflow $\ddagger(\mathbf{n}=\mathbf{8 5})$ & $P$ value \\
\hline \multicolumn{5}{|l|}{ Clinical characteristics } \\
\hline Age, y & $75.53 \pm 7.59(76)$ & $75.36 \pm 7.87(77)$ & $75.29 \pm 8.72(77)$ & .960 \\
\hline Body mass index & $29.42 \pm 5.26(28.93)$ & $29.51 \pm 5.82(28.66)$ & $30.11 \pm 6.34(28.65)$ & .873 \\
\hline Male gender & $56(71)$ & $50(65)$ & $58(68)$ & .727 \\
\hline $\mathrm{CAD}>50 \%$ in $\geq 1$ vessel & $31(39)$ & $26(34)$ & $31(36)$ & .777 \\
\hline CHF & $4(5)$ & $5(6)$ & $6(7)$ & .864 \\
\hline Chronic kidney disease & $3(4)$ & $3(40)$ & $1(1)$ & .500 \\
\hline COPD & $5(6)$ & $10(13)$ & $9(11)$ & .371 \\
\hline Diabetes mellitus & $15(19)$ & $15(19)$ & $23(27)$ & .373 \\
\hline \multicolumn{5}{|l|}{ Etiology of aortic valve disease } \\
\hline Congenital bicuspid & $13(16)$ & $19(25)$ & $16(18)$ & .417 \\
\hline Degenerative senile calcific & $62(78)$ & $56(73)$ & $64(75)$ & .704 \\
\hline Rheumatic/other & $4(6)$ & $2(2)$ & $5(7)$ & .397 \\
\hline Prior MI & $10(13)$ & $7(9)$ & $7(8)$ & .610 \\
\hline NYHA class III-IV & $38(49)$ & $38(50)$ & $32(38)$ & .217 \\
\hline Prior cardiovascular surgery & $3(4)$ & $5(6)$ & $3(4)$ & .615 \\
\hline Renal failure (dialysis dependent) & $2(3)$ & $1(1)$ & $0(0)$ & .343 \\
\hline \multicolumn{5}{|l|}{ Rhythm } \\
\hline Atrial fibrillation/flutter & $6(8)$ & $5(6)$ & $3(4)$ & .513 \\
\hline Normal sinus & $70(89)$ & $65(84)$ & $76(89)$ & .592 \\
\hline Other & $3(4)$ & $7(9)$ & $6(7)$ & .407 \\
\hline Smoking history & $1(1)$ & $2(3)$ & $2(2)$ & .823 \\
\hline Systemic hypertension & $58(73)$ & $47(61)$ & $59(69)$ & .239 \\
\hline TIA/CVA & $7(9)$ & $7(9)$ & $2(2)$ & .143 \\
\hline \multicolumn{5}{|l|}{ Perioperative outcomes } \\
\hline CPB time, $\min$ & $86.65 \pm 76.26(71)$ & $83.94 \pm 43.26(75)$ & $81.68 \pm 41.65(71)$ & .868 \\
\hline Isolated AVR bypass time, min & $53.22 \pm 18.82(47)$ & $58.63 \pm 22.10(55.5)$ & $61.53 \pm 23.19(59)$ & .289 \\
\hline Crossclamp time, $\min$ & $63.54 \pm 31.01(58)$ & $66.22 \pm 32.14(57)$ & $64.91 \pm 30.34(54)$ & .859 \\
\hline Concomitant procedure & $43(54)$ & $39(51)$ & $45(53)$ & .893 \\
\hline Hospital stay, d & $6.24 \pm 2.45(6)$ & $6.23 \pm 3.56(5)$ & $6.12 \pm 2.20(6)$ & .950 \\
\hline Severe PPM $\left(\right.$ AVAi $\left.<0.6 \mathrm{~cm}^{2} / \mathrm{m}^{2}\right)$ & $2(3)$ & $4(5)$ & $3(4)$ & .619 \\
\hline
\end{tabular}

Values are presented as mean \pm standard deviation (median) or n (\%). CAD, Coronary artery disease; $C H F$, congestive heart failure; $C O P D$, chronic obstructive pulmonary disease; $M I$, myocardial infarction; $N Y H A$, New York Heart Association; $T I A$, transient ischemic attack; $C V A$, cerebrovascular accident; $C P B$, cardiopulmonary bypass; $A V R$, aortic valve replacement; $P P M$, patient-prosthesis mismatch; $A V A i$, aortic valve area index. *Epic (St Jude, St Paul, Minn). $\dagger$ Magna (Edwards LifeSciences Inc, Irvine, Calif). $\ddagger$ Mitroflow (Sorin Biomedica Spa, Saluggio, Italy).

$P=.762)$. Follow-up echocardiography was performed at a median of 12 months (interquartile range, 11-14 months) following AVR (Table 3). Ejection fraction at 1 year was comparable between groups $(P=.879)$. Cardiac index was slightly lower for Epic than for Mitroflow $(P=.004)$, but no different between Epic and Magna $(P=.384)$ or Magna and Mitroflow $(P=.066)$. Evaluating the aortic prosthesis, AVA was comparable between groups at 1 year $(P=.067)$. When indexed to body surface area; however, AVAi was slightly greater in Magna than Epic $(P=.017)$, but not different between Magna and Mitroflow $(P=.098)$ or Epic and Mitroflow $(P=.197)$. Mean gradient was significantly lower for Magna than Epic and Mitroflow (both $P$ s $<.001$ ); however, there was no difference between Mitroflow and Epic $(P=.304)$. Peak velocity was lower for Magna than for Epic and Mitroflow (both $P$ s $<.001$ ), but comparable between Epic and Mitroflow $(P=.512)$. Stroke work loss was lowest in Magna compared with Epic $(P=.004)$ and Mitroflow $(P<.001)$; however, there was no difference in stroke work loss between Epic and Mitroflow $(P=.108)$. There was no difference in indexed LV mass between groups at 1 year $(P=.194)$.

In a secondary analysis, and using multiple imputation methods, we increased the number of patients with echocardiographic follow-up data to 241 patients (ie, all patients with clinical follow-up). We imputed missing mean gradient, AVA, AVAi, and LV mass index values. Reassuringly, the trends and statistical significance of relative hemodynamic performance between Epic, Magna, and Mitroflow valves at 1 year were unchanged (Table E1).

Controlling for variability in hemodynamic performance across physiologically differing valve sizes, we divided 
TABLE 2. Adverse clinical outcomes at 1-year follow-up

\begin{tabular}{lllcc}
\hline \multicolumn{1}{c}{ Variable } & $\begin{array}{c}\text { Epic* } \\
(\mathbf{n = 7 9 )}\end{array}$ & $\begin{array}{c}\text { Magna } \dagger \\
(\mathbf{n = 7 7 )}\end{array}$ & $\begin{array}{c}\text { Mitroflow } \ddagger \\
(\mathbf{n = 8 5 )}\end{array}$ & $\boldsymbol{P \text { value }}$ \\
\hline Postdischarge mortality & $3(3.7)$ & $4(4.9)$ & $2(2.3)$ & .654 \\
CVA/TIA & $0(0)$ & $0(0)$ & $0(0)$ & $>.99$ \\
CHF episode & $1(1.3)$ & $1(1.3)$ & $4(4.7)$ & .265 \\
Atrial fibrillation/flutter & $8(10.1)$ & $11(14.3)$ & $8(9.4)$ & .577 \\
Reoperation & $0(0)$ & $0(0)$ & $0(0)$ & $>.99$ \\
\hline
\end{tabular}

Values are presented as counts (\%). CVA, Cerebrovascular accident; TIA, transient ischemic attack; CHF, congestive heart failure. *Epic (St Jude, St Paul, Minn). $\dagger$ Magna (Edwards LifeSciences Inc, Irvine, Calif). † Mitroflow (Sorin Biomedica Spa, Saluggio, Italy).

patients into 3 groups according to commercially labeled implant size: Nos. 19 and $21(\mathrm{n}=68)$, No. $23(\mathrm{n}=65)$, or Nos. 25 and $27(\mathrm{n}=84)$ (Table E2 and Figure 2). In patients receiving valve Nos. 19 and 21, there were no differences in AVA, AVAi, or mean gradient between Epic, Magna, and Mitroflow valves. Hemodynamic performance was equally comparable between all valve types among patients receiving a No. 23 valve. However, in patients with the largest valves (Nos. 25 and 27), AVA $(P<.001)$ and AVAi $(P=.004)$ were slightly greater, and mean gradient slightly lower $(P=.008)$ at 1 year in patients receiving the Magna valve.

Considering patients in categories of actual annular size measured by a calibrated universal sizer, we divided patients into groups of $<23 \mathrm{~mm}(\mathrm{n}=50), 23 \mathrm{~mm}(\mathrm{n}=69)$, and $>23$ $\mathrm{mm}(\mathrm{n}=98)$ (Table E3 and Figure 3). Among patients with the smallest measured annulus diameter $(<23 \mathrm{~mm})$, AVA, AVAi, and mean gradient were comparable between valve types. However, in patients with a 23-mm annulus, AVA $(P=.027)$ and AVAi $(P=.013)$ were slightly greater, whereas mean gradient was slightly lower $(P=.002)$ among the cohort receiving a Magna valve. Analogously, mean gradient was noticeably lower in patients receiving a Magna prosthesis with an annulus $>23 \mathrm{~mm}(P<.001)$. We observed similar trends at 1 year in patients stratified according to $\mathrm{LV}$ outflow tract size (Table E4).

Evaluating the effect of AVR on LV remodeling, among all patients mean LV mass index regression between preoperative and 1-year postoperative echocardiography was $-16.1 \pm 27.6 \mathrm{~g} / \mathrm{m}^{2}(P<.001)$. Total LV mass index regression (Epic, $-18.9 \pm 28.7$; Magna, $-18.4 \pm 32.2$; Mitroflow, $-11.7 \pm 21.6 ; P=.262$ ) (Figure 4) and percent change in indexed LV mass (Epic, $-12 \%$; Magna, $-12 \%$; Mitroflow, $-8 \% ; P=.245)$ were comparable between groups of patients receiving different valves. Although male gender $(P=.029)$, increased preoperative mean gradient $(P=.018)$ and preoperative LV mass index $(P<.001)$ were univariate predictors of greater regression of indexed LV mass at 1 year, when adjusting for covariates greater preoperative LV mass index was the only independent predictor of improved regression $(P<.001)$ (Table E5).

\section{DISCUSSION}

We report midterm follow-up data of a randomized trial of 3 contemporary biologic aortic valve substitutes. The trends identified in the early postoperative period do not appear to be transient, because we now report persistence of these hemodynamic differences 1 year following AVR. Specifically, hemodynamic performance was comparable between the 3 valves in patients with a small $(<23 \mathrm{~mm})$ annular diameter. In those with a 23-mm annulus receiving the Magna, mean gradient was slightly lower, whereas AVA and AVAi were slightly greater. In patients with the largest $(>23 \mathrm{~mm})$ annular diameter, Magna was again associated with a slightly lower mean gradient, although AVA and AVAi were statistically similar between prostheses. Despite sustained differences in hemodynamic performance, clinical outcomes, including all-cause mortality, were comparable between groups. Although regression of LV mass index between preoperative and 1-year echocardiography was significant in all patients, it was indistinguishable among Epic, Magna, and Mitroflow groups. Coincident with this, we report excellent durability in all prosthesis types at 1 year.

The question of mechanical versus biological prosthetic valve at AVR requires consideration of patient age, need for anticoagulation, bleeding risk, and valve durability among other factors. ${ }^{17}$ When proceeding with implantation of a biologic prosthesis, the final choice of implant (ie, porcine vs pericardial or current vs prior generation) is often

TABLE 3. Hemodynamic performance at 1 year after aortic valve repair

\begin{tabular}{|c|c|c|c|c|}
\hline Variable & Epic* $(n=71)$ & $\operatorname{Magna}\lceil(\mathbf{n}=\mathbf{6 8})$ & Mitroflow $\ddagger(\mathbf{n}=78)$ & $P$ value \\
\hline Mean gradient, $\mathrm{mm} \mathrm{Hg}$ & $15.16 \pm 5.48(15)$ & $12.27 \pm 4.30(12)$ & $16.24 \pm 5.69(15.5)$ & $<.001$ \\
\hline Aortic valve area, $\mathrm{cm}^{2}$ & $1.81 \pm 0.50(1.72)$ & $2.02 \pm 0.54(1.99)$ & $1.89 \pm 0.57(1.81)$ & .067 \\
\hline Aortic valve area index, $\mathrm{cm}^{2} / \mathrm{m}^{2}$ & $0.92 \pm 0.28(0.85)$ & $1.04 \pm 0.28(1.03)$ & $0.96 \pm 0.26(0.89)$ & .015 \\
\hline Cardiac index, $\mathrm{L} / \mathrm{min} / \mathrm{m}^{2}$ & $3.17 \pm 0.68(3.05)$ & $3.34 \pm 0.83(3.21)$ & $3.48 \pm 0.68(3.21)$ & .035 \\
\hline Ejection fraction, $\%$ & $60.44 \pm 9.16(63.00)$ & $61.25 \pm 8.94(64.00)$ & $60.75 \pm 10.00(64.00)$ & .879 \\
\hline Peak velocity, m/s & $2.60 \pm 0.44(2.6)$ & $2.34 \pm 0.40(2.3)$ & $2.66 \pm 0.44(2.6)$ & $<.001$ \\
\hline Stroke work loss, $\%$ & $10.36 \pm 3.49(10.45)$ & $8.68 \pm 2.70(8.08)$ & $11.46 \pm 3.82(11.26)$ & $<.001$ \\
\hline Left ventricular mass index, $\mathrm{g} / \mathrm{m}^{2}$ & $104.86 \pm 25.16(101)$ & $99.76 \pm 25.1(97)$ & $106.28 \pm 23.48(106)$ & .194 \\
\hline
\end{tabular}

Values are presented as mean \pm standard deviation (median). *Epic (St Jude, St Paul, Minn). $\dagger$ Magna (Edwards LifeSciences Inc, Irvine, Calif). $\ddagger$ Mitroflow (Sorin Biomedica Spa, Saluggio, Italy). 
Mean Gradient Stratified by Implant Size

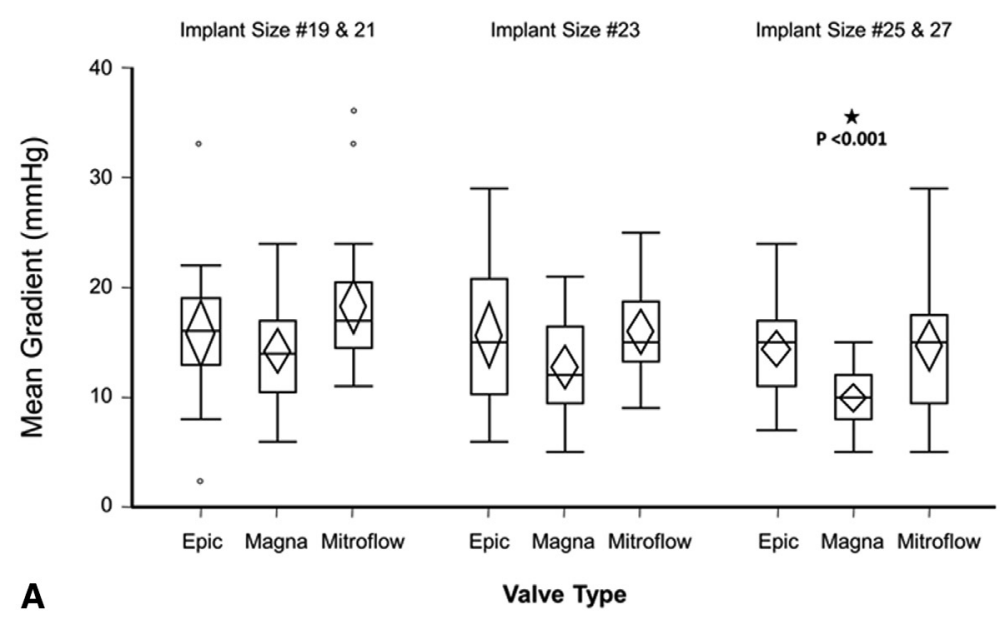

Aortic Valve Area Stratified by Implant Size

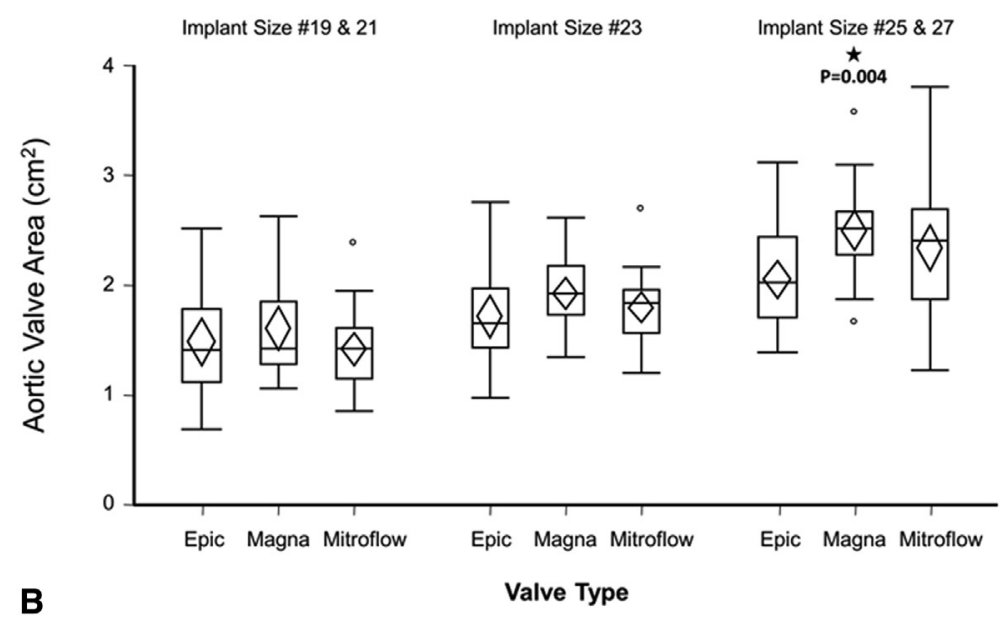

Aortic Valve Area Index Stratified by Implant Size

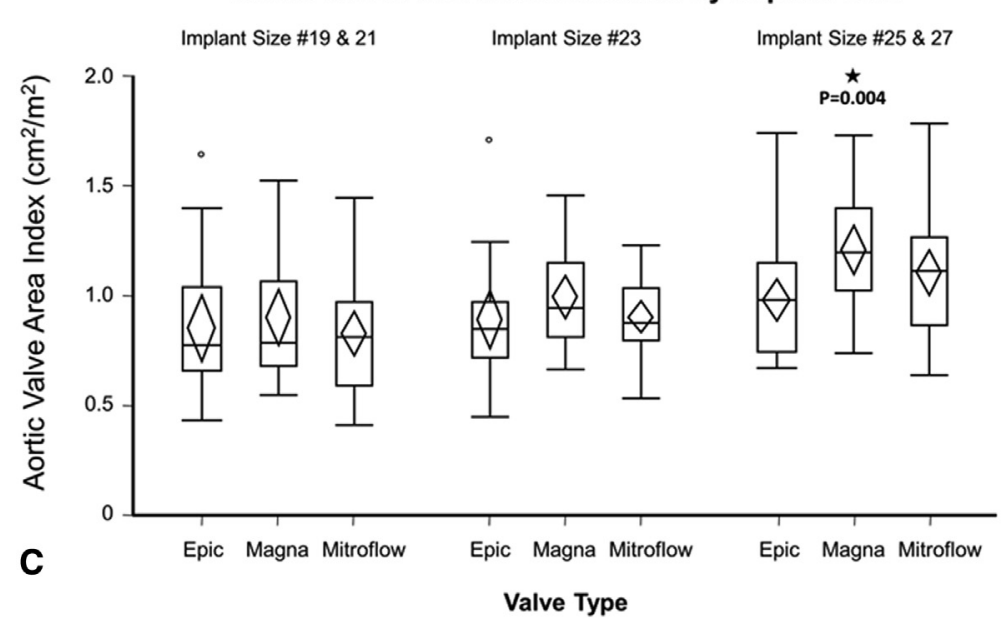

FIGURE 2. One-year aortic valve prosthesis hemodynamic parameters stratified by labeled valve size: Nos. 19 and 21, No. 23, and Nos. 25, and 27. A, Mean gradient was significantly lower in the Magna group for large size (Nos. 25 and 27) devices. B, Aortic valve area was significantly higher in the Magna group for large size (Nos. 25 and 27) devices. C, Indexed aortic valve area was significantly higher in the Magna group for large size (Nos. 25 and 27) devices. Means and medians are represented by diamonds and lines inside the box respectively. Top and bottom box borders encompass the middle 50\% of the data. Start indicates statistically significant comparison. Epic (St Jude, St Paul, Minn), Magna (Edwards LifeSciences Inc, Irvine, Calif), and Mitroflow (Sorin Biomedica Spa, Saluggio, Italy). 


\section{Mean Gradient Stratified by Universal Annulus Size}

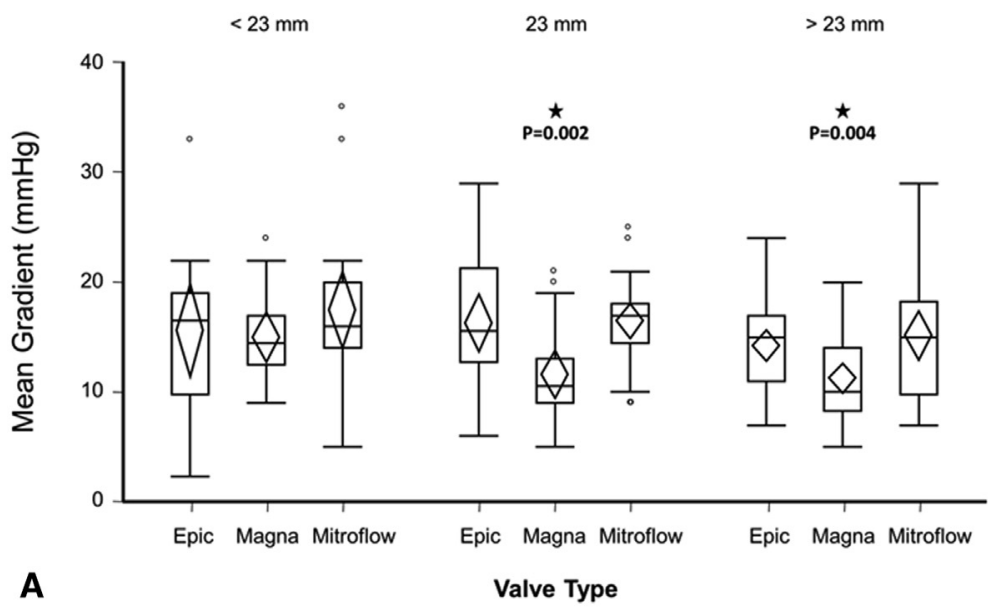

Aortic Valve Area Stratified by Universal Annulus Size

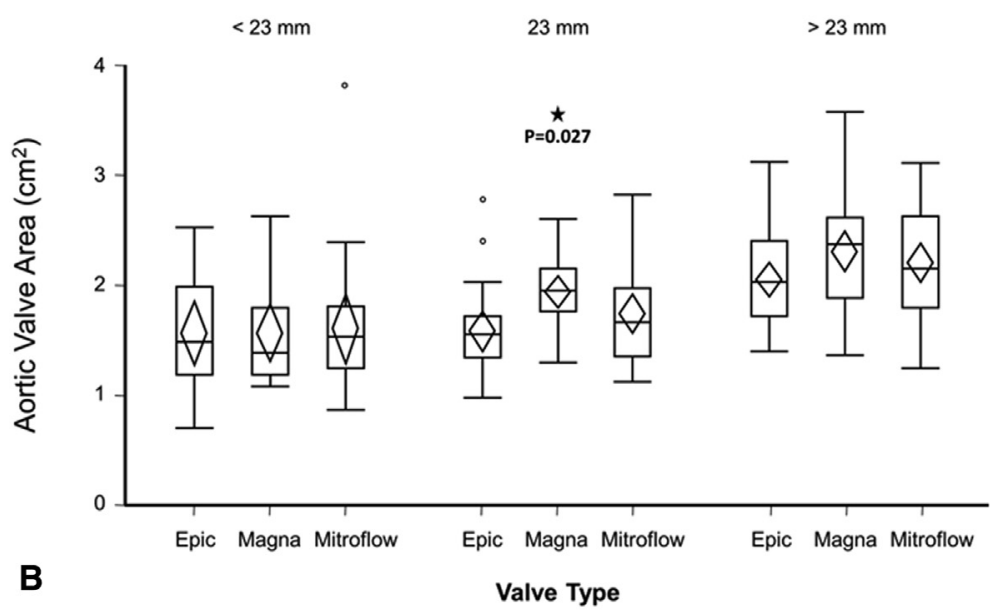

Aortic Valve Area Index Stratified by Universal Annulus Size

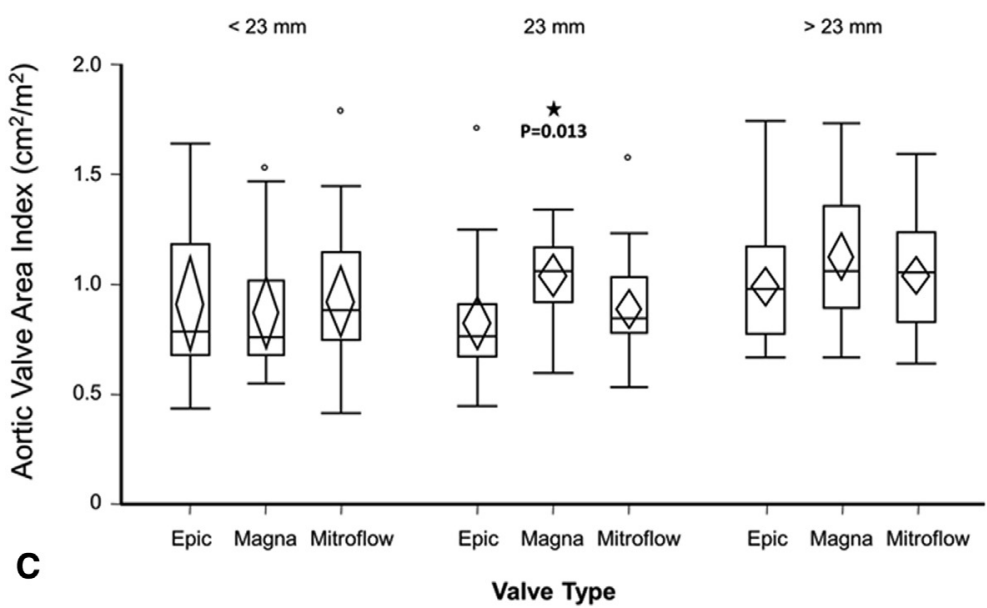

FIGURE 3. One-year aortic valve prosthesis hemodynamic parameters stratified by actual annular size (universal sizer) measured directly at surgery: $<23$ $\mathrm{mm}, 23 \mathrm{~mm}$, and $>23 \mathrm{~mm}$. A, Mean gradient was significantly lower in the Magna group for patients with a mid-size (23 mm) and large (>23 mm) annulus. $\mathrm{B}$, Aortic valve area was significantly higher in the Magna group in patients with a midsize $(23 \mathrm{~mm})$ annulus. C, Indexed aortic valve area were significantly higher in the Magna group in patients with a midsize $(23 \mathrm{~mm})$ annulus. Means and medians are represented by diamonds and lines inside the box, respectively. Top and bottom box borders encompass the middle 50\% of the data. Start indicates statistically significant comparison. Epic (St Jude, St Paul, Minn), Magna (Edwards LifeSciences Inc, Irvine, Calif), and Mitroflow (Sorin Biomedica Spa, Saluggio, Italy). 


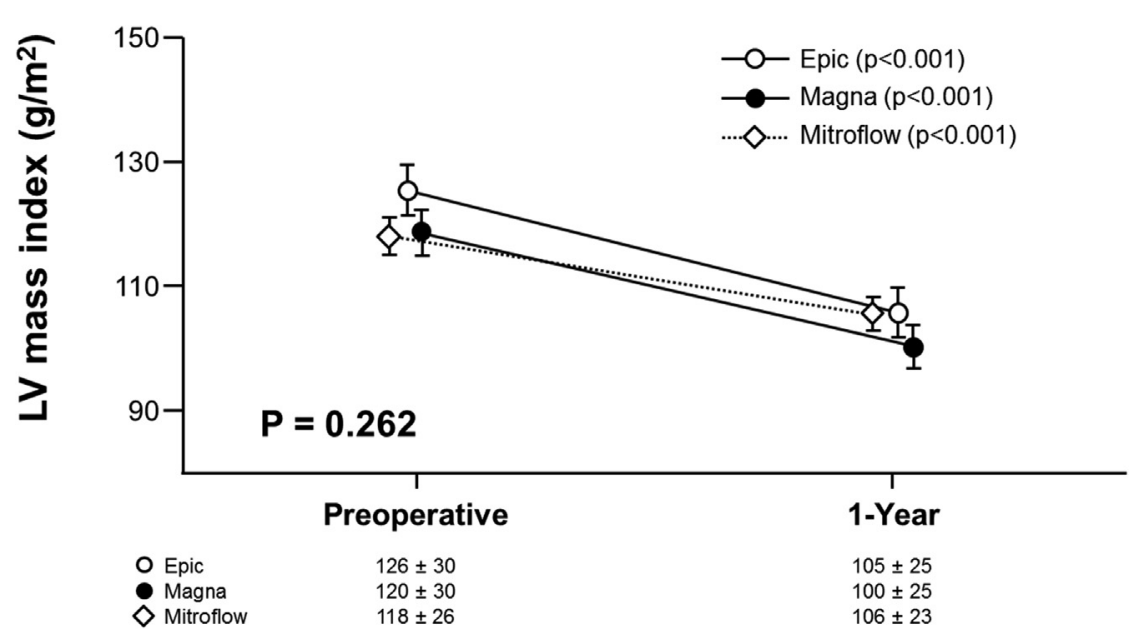

FIGURE 4. Left ventricular ( $L V)$ mass index regression in Epic (St Jude, St Paul, Minn), Magna (Edwards LifeSciences Inc, Irvine, Calif), and Mitroflow (Sorin Biomedica Spa, Saluggio, Italy) groups. Regression in indexed LV mass from preoperative to 1-year postoperative assessment was significant within Epic, Magna, and Mitroflow groups $(P<.001)$, but comparable among groups $(P=.262)$. The graph shows means and standard error of the mean $(m e a n s \pm$ $\mathrm{SD}$ at each time point are shown below the graph).

influenced by hemodynamic performance profiles. In patients with severe aortic stenosis the ideal prosthetic valve affords a large effective orifice area/AVA, minimizes transvalvular gradient, and thus facilitates regression of LV hypertrophy. ${ }^{18}$ Whereas third generation biologic prosthetic aortic valves have been advertised as offering improved hemodynamic performance, ${ }^{3-7}$ to date there has been a paucity of data derived from prospective, randomized, head-to-head comparisons of current generation porcine and pericardial aortic valve prostheses. Accordingly, we recently randomized 300 patients to receive Epic, Magna, or Mitroflow aortic valves. ${ }^{9}$ Analyzing predismissal echocardiograms, we reported equivalent hemodynamic performance between the valves in patients with a small annulus size $(<23 \mathrm{~mm})$, but slightly and significantly lower mean gradients in patients with a larger annulus $\left(>23 \mathrm{~mm}\right.$ ) receiving the Magna. ${ }^{9}$ Of importance, early hemodynamic measurements-particularly relatively flow-dependent parameters such as mean gradient and peak velocity-may be biased by several transient states in the immediate postoperative window, such as chest wound healing, depressed ejection fraction, and/or a hyperdynamic state secondary to anemia, ${ }^{19}$ thus necessitating reexamination of valve performance in the months following hospital dismissal.

Midterm hemodynamic profiles of Epic, Magna, and Mitroflow aortic valve prostheses were comparable to results reported in prior studies. ${ }^{5,6,20-23}$ Mean gradient at 1 year in the Epic group ranged from 14.4 (Nos. 25 and 27) to $15.8 \mathrm{~mm} \mathrm{Hg}$ (Nos. 19 and 21), similar to findings by Bobiarski and colleagues ${ }^{20}$ reporting 1-year measurements, but slightly greater than those reported by Maitland at 6 months post-AVR. ${ }^{21}$ Conversely, AVA and AVAi in our population, although analogous to values presented by
Maitland and colleagues, ${ }^{21}$ were greater than those reported by Bobiarski and colleagues. ${ }^{20}$ In patients receiving the Magna valve, mean gradient was between 10 (Nos. 25 and 27) and $14.2 \mathrm{~mm} \mathrm{Hg}$ (Nos. 19 and 21), in line with 1-year estimates from Dalmau and colleagues, ${ }^{5,22}$ and Bobiarski and colleagues. ${ }^{20}$ Although reports of AVA and AVAi from Dalmau and colleagues ${ }^{5,22}$ were similar to our own, our measurements were greater than those of Bobiarski and colleagues. ${ }^{20} \mathrm{We}$ observed a similar pattern in the Mitroflow group, whereby mean gradient recorded in our cohort was marginally greater than measurements from Jamieson and colleagues ${ }^{6} 11$ months post-AVR, and Conte and colleagues ${ }^{23} 1$ year following valve implantation. In contrast, AVA and AVAi values in our study were slightly greater than estimates reported by both Jamieson and colleagues ${ }^{6}$ and Conte and colleagues ${ }^{23}$ studying the Mitroflow. Overall, although somewhat greater mean gradients were evident in our study compared with prior reports, it is encouraging that less flow-dependent parameters such as AVA and AVAi were similar to historical estimates. For example, although Conte and colleagues ${ }^{23}$ recorded lower mean gradients in patients with the Mitroflow valve, on closer examination it is apparent that cardiac index ranged between 2.3 and $2.6 \mathrm{~L} / \mathrm{min} / \mathrm{m}^{2}$ in their study, versus $3.5 \mathrm{~L} / \mathrm{min} / \mathrm{m}^{2}$ in our report. By extension, it seems logical that impaired LV forward flow may have resulted in an underestimate of mean gradient, and thus less flow-dependent parameters such as AVA and AVAi may represent more objective indices of hemodynamic performance.

Although our analysis demonstrates that small early hemodynamic differences between Epic, Magna, and Mitroflow valves mostly persist 1 year following AVR, we note several subtle differences. Whereas early postoperative 
echocardiography demonstrated slightly reduced mean gradient and increased AVA and AVAi in patients receiving a No. 23 Magna device, ${ }^{9}$ these trends were no longer statistically significant at 1-year follow-up. Nevertheless, the modestly improved performance of the Magna valve versus Epic and Mitroflow in patients with larger (No. 25 and 27) implant sizes was sustained at midterm evaluation. Heterogeneity in commercial valve dimensions may result in invalid hemodynamic comparisons, thus emphasizing the importance of correcting for aortic annulus size. ${ }^{6,9,21,24}$ We therefore evaluated echocardiographic valve performance at 1 year after stratifying patients by annular size as determined by a calibrated universal sizer, and echocardiographic measurement of LV outflow tract dimensions. As observed in the early postoperative period, ${ }^{9}$ patients with small $(<23 \mathrm{~mm})$ annular diameters were comparable between the 3 groups across all hemodynamic parameters. However, in patients with a 23-mm annular diameter, early trends of slightly lower mean gradient and greater AVA in the Magna group reached statistical significance at 1 year. Further, slightly lower gradients in patients with large $(>23 \mathrm{~mm})$ annular sizes receiving a Magna valve remained significant at mid-term evaluation. Stratification by LV outflow tract dimensions yielded similar results. Despite the statistically significant differences in hemodynamic performance between the 3 valves, it warrants emphasis that the differences are clinically insignificant, and the Epic, Magna, and Mitroflow valves appear to perform very well at 1-year follow-up. This should serve as reassurance to surgeons currently implanting these prosthetic valves, and to those considering the adoption of these valve substitutes into their clinical practice.

The influence of early postoperative hemodynamic discrepancies among valve types on clinical outcome after 1 year is unclear. Much emphasis has been placed on the potential deleterious influence of patient-prosthesis mismatch — and associated hemodynamic abnormalitieson postoperative outcomes. Various studies, including 2 recent meta-analyses, have shown that patient-prosthesis mismatch predicts increased early and late death. ${ }^{25-29}$ It may therefore be proposed that subtle yet significant differences in hemodynamic performance between valves may similarly yield variable survival rates. However, our data suggest that differences in hemodynamic parameter performance do not warrant concern, because they do not appear to influence survival among the studied valve types at 1-year follow-up. Encouragingly, whereas Conte and colleagues $^{23}$ and Asch and colleagues ${ }^{30}$ previously detailed that survival free from all-cause mortality following implant of the Mitroflow valve was $85.8 \%$ and $89.8 \%$, respectively, we report that 1-year survival was $95.8 \%, 96.8 \%$, and $97.9 \%$ in the Epic, Magna, and Mitroflow valves, respectively $(P=.577)$ in our randomized population.
Further considering that cardiovascular morbidity, including stroke/transient ischemic attack, congestive heart failure, and atrial fibrillation/flutter were not different between the 3 valve types, it would seem that differences in hemodynamic performance between prostheses may not translate to differences in morbidity or mortality at 1-year post-AVR.

Despite clinically small but persistent differences in hemodynamic performance between Epic, Magna, and Mitroflow valves at 1 year, indexed LV mass regression was consistent between groups $(P=.262)$. This echoes the findings of Bobiarski and colleagues ${ }^{20}$ that reported a slightly advantageous hemodynamic profile in 33 patients receiving the Magna valve versus 36 implanted with the Epic, but comparable LV mass index regression at 1 year between the 2 groups (Magna, $-6.8 \mathrm{~g} / \mathrm{m}^{2}$ vs Epic, -10.4 $\left.\mathrm{g} / \mathrm{m}^{2} ; P=.57\right)$. In a randomized evaluation of 54 patients with Magna versus 54 patients with the Mosaic valve (Medtronic Inc, Minneapolis, Minn), Dalmau and colleagues ${ }^{5,22}$ again documented that variable hemodynamic performance at 1 year was not associated with differences in LV mass index regression (Magna, -30.1 vs Mosaic -26.3; $P=.8$ ). Our finding that preoperative LV mass index was the only independent predictor of improved LV mass index regression at 1 year is also consistent with prior reports. ${ }^{31-34}$ Ultimately our data suggests that small postoperative hemodynamic differences among currentgeneration bioprosthetic valves do not appear to influence the reversal rate of baseline LV hypertrophy at 1 year.

Mid-to-long-term durability is an important metric in evaluating the relative merits of current generation bioprosthetic valves. Specifically, in elderly patients in whom biologic prosthetic valves are commonly indicated, ${ }^{35}$ the expectation is that the valve is of sufficient durability that the patient will not require a second procedure during their lifetime. Indeed, risk of a second procedure-especially in the very elderly-may be prohibitive. Nevertheless, in our study we document excellent 1-year durability for all valve types, with no patients requiring reintervention on the aortic valve. This is in keeping with various prior reports that demonstrate a $>99 \%$ freedom from structural valve deterioration or reoperation at 1-year follow-up. ${ }^{7,23,30,36}$ Considering that the estimated life span of earlier generation prosthetic aortic valves is approximately 10 to 15 years, our finding is to be expected. Although our data at 1-year follow-up does not allow us to definitively comment on which current generation valve type has a superior durability profileporcine versus pericardial-continued longitudinal follow-up and monitoring of hemodynamic and clinical outcomes may shed further light on this matter.

\section{Limitations}

Although 1-year clinical follow-up was only available in $80 \%$ of patients $(\mathrm{n}=241)$ and echocardiographic data was 
available in $72 \%$ of patients $(n=217)$, we have no reason to believe that patients in whom midterm data was not obtained were systematically different. Geographic and financial barriers were the primary limiting factors cited among all patients who dropped out of the study. Yet the number of patients unavailable for follow-up in the Epic, Magna, and Mitroflow groups were similar (Figure 1), and the baseline characteristics of the 241 patients evaluated at 1 year were comparable, suggesting preservation of baseline randomization. Importantly, all patients who dropped out of the study did so on their own behalf when contacted by telephone at 1 year follow-up, providing reassurance with regard to their midterm vital status. Further, when indicating their desire to drop out, all patients noted that they had not undergone reoperative procedures on the aortic valve. Encouragingly, following the use of multiple imputation methods to increase the number of patients with complete echocardiographic data, we noted that trends and statistical significance levels of hemodynamic performance between valve types were maintained. Given that previous generations of bioprosthetic aortic valves have been estimated to have a durability of approximately 10 to 15 years, evaluation of this metric at 1-year may be too soon to allow for definitive commentary on the relative durability of the 3 studied valves. We anticipate that the continued monitoring and future reporting of longitudinal follow-up in these patients will further shed light on this matter.

\section{CONCLUSIONS}

Despite midterm persistence of hemodynamic differences amongst current third-generation aortic valve substitutes, these discrepancies are clinically small and do not translate to significant differences in morbidity, mortality, valve durability, or LV remodeling at 1-year follow-up. Our prospective, randomized study suggests that the Epic, Magna, and Mitroflow valves have favorable 1-year hemodynamic performance profiles and clinical outcomes. These encouraging trends must continue to be assessed during longitudinal follow-up.

\section{References}

1. David TE, Armstrong S, Maganti M. Hancock II bioprosthesis for aortic valve replacement: the gold standard of bioprosthetic valves durability? Ann Thorac Surg. 2010;90:775-81.

2. Said SM, Ashikhmina E, Greason KL, Suri RM, Park SJ, Daly RC, et al. Do pericardial bioprostheses improve outcome of elderly patients undergoing aortic valve replacement? Ann Thorac Surg. 2012;93:1868-74; discussion 1874-5.

3. Borger MA, Nette AF, Maganti M, Feindel CM. Carpentier-Edwards Perimount Magna valve versus Medtronic Hancock II: a matched hemodynamic comparison. Ann Thorac Surg. 2007;83:2054-8.

4. Botzenhardt F, Eichinger W, Guenzinger R, Bleiziffer S, Wagner I, Bauernschmitt R, et al. Hemodynamic performance and incidence of patientprosthesis mismatch of the complete Supraannular Perimount Magna bioprosthesis in the aortic position. Thorac Cardiovasc Surg. 2005;53:226-30.
5. Dalmau MJ, González-Santos JM, Blázquez JA, Sastre JA, López-Rodríguez J, Bueno M, et al. Hemodynamic performance of the Medtronic Mosaic and Perimount Magna aortic bioprostheses: five-year results of a prospectively randomized study. Eur J Cardiothorac Surg. 2011;39:844-52; discussion 852.

6. Jamieson W, Forgie W, Hayden R, Langlois Y, Ling H, Stanford E, et al. Hemodynamic performance of Mitroflow Aortic Pericardial bioprosthesis - optimizing managemetn for the small aortic annulus. Thorac Cardiov Surg. 2010;58: 69-75.

7. Jamieson WRE, Lewis CTP, Sakwa MP, Cooley DA, Kshettry VR, Jones KW, et al. St Jude Medical Epic porcine bioprosthesis: results of the regulatory evaluation. J Thorac Cardiovasc Surg. 2011;141:1449-54.e2.

8. Chan V, Malas T, Lapierre H, Boodhwani M, Lam B-K, Rubens FD, et al. Reoperation of left heart valve bioprostheses according to age at implantation. $\mathrm{Circu}$ lation. 2011;124(11 Suppl):S75-80.

9. Suri RM, Michelena HI, Burkhart HM, Greason KL, Daly RC, Dearani JA, et al. A prospective, randomized comparison of 3 contemporary bioprosthetic aortic valves: should hemodynamic performance influence device selection? J Thorac Cardiovasc Surg. 2012;144:1387-95. 1398; discussion 1395-7.

10. Quinones MA, Waggoner AD, Reduto LA, Nelson JG, Young JB, Winters WL, et al. A new, simplified and accurate method for determining ejection fraction with two-dimensional echocardiography. Circulation. 1981;64:744-53.

11. Rich S, Sheikh A, Gallastegui J, Kondos G, Mason T, Lam W. Determination of left ventricular ejection fraction by visual estimation during real-time twodimensional echocardiography. Am Heart J. 1982;104:603-6.

12. Quiñones MA, Otto CM, Stoddard M, Waggoner A, Zoghbi WA. Recommendations for quantification of Doppler echocardiography: a report from the Doppler quantification task force of the nomenclature and standards committee of the American Society of Echocardiography. J Am Soc Echocariogr. 2002;15:167-84.

13. Bermejo J, Odreman R, Feijoo J, Moreno MM, Gómez-Moreno P, GarcíaFernández MA. Clinical efficacy of Doppler-echocardiographic indices of aortic valve stenosis: a comparative test-based analysis of outcome. J Am Coll Cardiol. 2003;41:142-51.

14. Schiller N, Shah P, Crawford M, DeMaria A, Devereux R, Feigenbaum H, et al. Recommendations for quantitation of the left ventricle by two-dimensional echocardiography. American Society of Echocardiography Committee on Standards, Subcommittee on Quantitation of Two-Dimensional Echocardiograms. J Am Soc Echocariogr. 1989;2:358-67.

15. Gottdiener JS, Bednarz J, Devereux R, Gardin J, Klein A, Manning WJ, et al American Society of Echocardiography recommendations for use of echocardi ography in clinical trials. J Am Soc Echocariogr. 2004;17:1086-119.

16. Lang RM, Bierig M, Devereux RB, Flachskampf FA, Foster E, Pellikka PA, et al Recommendations for chamber quantification: a report from the American Society of Echocardiography's Guidelines and Standards Committee and the Chamber Quantification Writing Group, developed in conjunction with the European Association of Echocardiograph. J Am Soc Echocariogr. 2005;18:1440-63.

17. Suri RM, Schaff HV. Selection of aortic valve prostheses: contemporary reappraisal of mechanical versus biologic valve substitutes. Circulation. 2013;128: 1372-80.

18. Dumesnil JG, Honos GN, Lemieux M, Beauchemin J. Validation and applications of indexed aortic prosthetic valve areas calculated by Doppler echocardiography. J Am Coll Cardiol. 1990;16:637-43.

19. Bonow RO, Carabello BA, Chatterjee K, de Leon AC, Faxon DP, Freed MD, et al. ACC/AHA 2006 Guidelines for the Management of Patients With Valvular Heart Disease: a Report of the American College of Cardiology/American Heart Association Task Force on Practice Guidelines. J Am Coll Cardiol. 2006;48: e1-148.

20. Bobiarski J, Newcomb AE, Elhenawy AM, Maganti M, Bos J, Hemeon S, et al. One-year hemodynamic comparison of Perimount Magna with St Jude Epic aortic bioprostheses. Arch Med Sci. 2013;9:445-51.

21. Maitland A, Hirsch GM, Pascoe E. Hemodynamic performance of the St. Jude Medical Epic Supra aortic stented valve. J Heart Valve Dis. 2011;20:327-31.

22. Dalmau MJ, Maríagonzález-Santos J, López-Rodríguez J, Bueno M, Arribas A. The Carpentier-Edwards Perimount Magna aortic xenograft: a new design with an improved hemodynamic performance. Interact Cardiovasc Thorac Surg. 2006;5:263-7.

23. Conte J, Weissman N, Dearani JA, Bavaria J, Heimansohn D, Dembitsky W, et al A North American, prospective, multicenter assessment of the Mitroflow aortic pericardial prosthesis. Ann Thorac Surg. 2010;90:144-52, e1-3.

24. Seitelberger R, Bialy J, Gottardi R, Seebacher G, Moidl R, Mittelböck M, et al. Relation between size of prosthesis and valve gradient: comparison of two aortic bioprosthesis. Eur J Cardiothorac Surg. 2004;25:358-63. 
25. Head SJ, Mokhles MM, Osnabrugge RLJ, Pibarot P, Mack MJ, Takkenberg JJM, et al. The impact of prosthesis-patient mismatch on long-term survival after aortic valve replacement: a systematic review and meta-analysis of 34 observational studies comprising 27186 patients with 133141 patient-years. Eur Heart J. 2012;33:1518-29.

26. Takagi H, Yamamoto H, Iwata K, Goto S, Umemoto T. A meta-analysis of effects of prosthesis -patient mismatch after aortic valve replacement on late mortality. Int J Cardiol. 2012;159:150-4.

27. Pibarot P, Dumesnil JG. Valve prosthesis-patient mismatch, 1978 to 2011: from original concept to compelling evidence. J Am Coll Cardiol. 2012;60:1136-9.

28. Blais C, Dumesnil JG, Baillot R, Simard S, Doyle D, Pibarot P. Impact of valve prosthesis-patient mismatch on short-term mortality after aortic valve replacement. Circulation. 2003;108:983-8.

29. Mohty D, Mohty-Echahidi D, Malouf JF, Girard SE, Schaff HV, Grill DE, et al. Impact of prosthesis-patient mismatch on long-term survival in patients with small St Jude Medical mechanical prostheses in the aortic position. Circulation. 2006;113:420-6.

30. Asch FM, Heimansohn D, Doyle D, Dembitsky W, Ferdinand FD, Swanson J, et al. Mitroflow Aortic Bioprosthesis 5-year follow-up: North American Prospective Multicenter Study. Ann Thorac Surg. 2012;94:1198-203.
31. Suri RM, Zehr KJ, Sundt TM, Dearani JA, Daly RC, Oh JK, et al. Left ventricular mass regression after porcine versus bovine aortic valve replacement: a randomized comparison. Ann Thorac Surg. 2009;88:1232-7.

32. Del Rizzo D, Abdoh A, Cartier P, Doty D, Westaby S. Factors affecting left ventricular mass regression after aortic valve replacement with stentless valves. Semin Thorac Cardiovasc Surg. 1999;11(4 Suppl):1114-20.

33. Tasca G, Brunelli F, Cirillo M, DallaTomba M, Mhagna Z, Troise G, et al Impact of valve prosthesis-patient mismatch on left ventricular mass regression following aortic valve replacement. Ann Thorac Surg. 2005;79: 505-10.

34. Lim E, Ali A, Theodorou P, Sousa I, Ashrafian H, Chamageorgakis T, et al Longitudinal study of the profile and predictors of left ventricular mass regression after stentless aortic valve replacement. Ann Thorac Surg. 2008;85: 2026-9.

35. Nishimura RA, Otto CM, Bonow RO, Carabello BA, Erwin JP, Guyton RA, et al 2014 AHA/ACC guideline for the management of patients with valvular heart disease. J Am Coll Cardiol. 2014;1-234.

36. Yankah CA, Pasic M, Musci M, Stein J, Detschades C, Siniawski H, et al. Aortic valve replacement with the Mitroflow pericardial bioprosthesis: durability results up to 21 years. J Thorac Cardiovasc Surg. 2008;136:688-96.

\section{EDITORIAL COMMENTARY}

\section{A game of millimeters}

Davis C. Drinkwater, Jr, MD, MSc

See related article on pages 163-73.

The current issue of the Journal includes a report by Thalji and coauthors ${ }^{1}$ on a prospective, randomized trial of isolated aortic valve replacement with 3 commonly used bioprostheses. Early and 1-year echocardiographic data showed that the Magna valve (Edwards Lifesciences Corporation, Irvine, Calif) had a small $(<4 \mathrm{~mm})$ but persistent and significantly lower transvalvular gradient than either the Epic valve (St Jude Medical, Inc, St Paul, Minn) or the Mitroflow valve (Sorin Group USA, Inc, Arvada Colo). This intriguing potential benefit, with attendant calculated increase in indexed valve area, was confined to sizes larger than $23 \mathrm{~mm}$. Early similar gradient differences noted in the 23-mm group did not persist at 1 year. Not surprisingly, clinical outcomes including early

From Tristar Centennial Cardiovascular Surgery, Nashville, Tenn.

Disclosures: Author has nothing to disclose with regard to commercial support.

Received for publication Sept 22, 2014; accepted for publication Sept 22, 2014; available ahead of print Oct 22, 2014.

Address for reprints: Davis C. Drinkwater, Jr, MD, MSc, Tristar Centennial Cardiovascular Surgery, 2400 Patterson St, Suite 307 a, Nashville, TN (E-mail: davis. drinkwater@hcahealthcare.com).

J Thorac Cardiovasc Surg 2015;149:173-4

$0022-5223 / \$ 36.00$

Copyright (C) 2015 by The American Association for Thoracic Surgery

http://dx.doi.org/10.1016/j.jtcvs.2014.09.083 and midterm mortality and morbidity, left ventricular mass regression, and valve durability or need for reintervention $(\mathrm{N}=0)$ have been equivalent for these 3 popular and well-known valves. Thalji and coauthors ${ }^{1}$ emphasize that the small hemodynamic benefits at this point in the follow-up have no corresponding demonstrable clinical or physiologic findings, and this report should reassure the patients and doctors using any of the 3 valves. As increasing relative numbers of bioprostheses are implanted each year, further information on these 3 commonly used valves is welcome.

The study's strength is clearly the randomization format enforced at the time of implantation. This was likely very achievable because of the tertiary referral center of Thalji and coauthors, ${ }^{1}$ and most surgeons as well as patients enrolling in this trial (mean 75 years) would view these 3 valves as providing equivalent outcomes. On the other hand, challenges imposed by the large tertiary nature of their institution, the natural history of these elderly patients, and the "confidence" level of the patients in receiving the assigned valve has resulted in the major weakness of this trial, and that is the relatively large percentage of patients $(30 \%)$ without 1-year echocardiographic data who were effectively lost to follow-up (LTF). Because of the small hemodynamic differences and the relatively small trial, the availability of complete data for only $71 \%$ of the patients should cause readers to view the findings as preliminary at most and warranting 
TABLE E1. Hemodynamic performance at 1 year after imputation of missing values**

\begin{tabular}{|c|c|c|c|c|c|c|}
\hline \multirow[b]{2}{*}{ Variable } & \multirow{2}{*}{$\begin{array}{c}\text { Epic } \dagger \\
(n=79) \\
\end{array}$} & \multirow{2}{*}{$\begin{array}{l}\text { Magna } \\
(\mathbf{n}=77) \\
\end{array}$} & \multirow{2}{*}{$\begin{array}{c}\text { Mitroflow } \S \\
\quad(\mathbf{n}=\mathbf{8 5})\end{array}$} & \multicolumn{3}{|c|}{$P$ value } \\
\hline & & & & Epic vs Magna & Epic vs Mitroflow & Magna vs Mitroflow \\
\hline Mean gradient, $\mathrm{mm} \mathrm{Hg}$ & $15.17 \pm 7.92$ & $12.49 \pm 5.36$ & $16.05 \pm 8.13$ & .003 & .295 & $<.001$ \\
\hline Aortic valve area, $\mathrm{cm}^{2}$ & $1.81 \pm 0.82$ & $2.02 \pm 0.57$ & $1.90 \pm 0.85$ & .057 & .294 & .171 \\
\hline Aortic valve area index, $\mathrm{cm}^{2} / \mathrm{m}^{2}$ & $0.92 \pm 0.42$ & $1.04 \pm 0.28$ & $0.96 \pm 0.43$ & .0147 & .297 & .121 \\
\hline Left ventricular mass index, $\mathrm{g} / \mathrm{m}^{2}$ & $105.25 \pm 39.02$ & $100.05 \pm 25.95$ & $106.52 \pm 44.33$ & .238 & .792 & .180 \\
\hline
\end{tabular}

Variables are presented as mean \pm standard deviation. *Five multiple imputation datasets were created based on patient-specific values at preoperative and dismissal echocardiography, and nonmissing values at 1-year follow-up. Results of the 5 analytical sets were combined, and hemodynamic performance between valve types compared using missing value analysis procedures (SAS version 9.2; SAS Institute, Inc, Cary, NC). †Epic (St Jude, St Paul, Minn). ‡Magna (Edwards LifeSciences Inc, Irvine, Calif). §Mitroflow (Sorin Biomedica Spa, Saluggio, Italy).

TABLE E2. One-year echocardiogram data comparison stratified by implant size

\begin{tabular}{|c|c|c|c|c|c|}
\hline Implant size & Echocardiogram at 1 year & Epic* & Magna $†$ & Mitroflow $\ddagger$ & $P$ value \\
\hline \multirow[t]{4}{*}{ Nos. 19 and $21(n=68)$} & & $\mathrm{n}=20$ & $\mathrm{n}=23$ & $\mathrm{n}=25$ & \\
\hline & Mean gradient, $\mathrm{mm} \mathrm{Hg}$ & $15.82 \pm 6.39(16)$ & $14.22 \pm 4.57(14)$ & $18.28 \pm 5.85(17)$ & .052 \\
\hline & Aortic valve area, $\mathrm{cm}^{2}$ & $1.49 \pm 0.45$ & $1.62 \pm 0.45$ & $1.43 \pm 0.35$ & .28 \\
\hline & Aortic valve area index $\mathrm{cm}^{2} / \mathrm{m}^{2}$ & $0.86 \pm 0.31(0.78)$ & $0.90 \pm 0.24(0.79)$ & $0.83 \pm 0.24(0.82)$ & .65 \\
\hline \multirow[t]{4}{*}{ No. $23(n=65)$} & & $\mathrm{n}=20$ & $\mathrm{n}=21$ & $\mathrm{n}=24$ & \\
\hline & Mean gradient, $\mathrm{mm} \mathrm{Hg}$ & $15.65 \pm 6.23(15)$ & $12.76 \pm 4.29(12)$ & $16 \pm 4.70(15)$ & .081 \\
\hline & Aortic valve area, $\mathrm{cm}^{2}$ & $1.72 \pm 0.42(1.66)$ & $1.93 \pm 0.32(1.93)$ & $1.81 \pm 0.32(1.85)$ & .15 \\
\hline & Aortic valve area index $\mathrm{cm}^{2} / \mathrm{m}^{2}$ & $0.89 \pm 0.28(0.85)$ & $1.00 \pm 0.21(0.95)$ & $0.91 \pm 0.16(0.88)$ & .27 \\
\hline \multirow[t]{4}{*}{ Nos. 25 and $27(n=84)$} & & $\mathrm{n}=31$ & $\mathrm{n}=24$ & $\mathrm{n}=29$ & \\
\hline & Mean gradient, $\mathrm{mm} \mathrm{Hg}$ & $14.42 \pm 4.31(15)$ & $9.96 \pm 2.90(10)$ & $14.69 \pm 5.95(15)$ & $<.001 \S$ \\
\hline & Aortic valve area, $\mathrm{cm}^{2}$ & $2.06 \pm 0.46(2.03)$ & $2.51 \pm 0.40(2.52)$ & $2.35 \pm 0.54(2.41)$ & $.004 \|$ \\
\hline & Aortic valve area index $\mathrm{cm}^{2} / \mathrm{m}^{2}$ & $0.98 \pm 0.26(0.98)$ & $1.21 \pm 0.25(1.20)$ & $1.11 \pm 0.27(1.11)$ & $0.008 \rrbracket$ \\
\hline
\end{tabular}

Values are presented as mean \pm standard deviation (median). *Epic (St Jude, St Paul, Minn). †Magna (Edwards LifeSciences Inc, Irvine, Calif). $\ddagger$ Mitroflow (Sorin Biomedica Spa, Saluggio, Italy). §Mitroflow versus Magna, $P<.001$; Epic versus Magna, $P<.001$; and Mitroflow versus Epic, $P=.83$. $\|$ Mitroflow versus Magna, $P=.25$; Epic versus Magna $P=.001$; and Mitroflow versus Epic $P=.021$. $\uparrow$ Mitroflow versus Magna; $P=.33$; Epic versus Magna, $P=.006$; and Mitroflow versus Epic, $P=.161$.

TABLE E3. One-year echocardiogram data comparison stratified by universal size

\begin{tabular}{|c|c|c|c|c|c|}
\hline Universal size & Echocardiogram at 1 year & Epic* & Magna $†$ & Mitroflow $\ddagger$ & $P$ value \\
\hline \multirow[t]{4}{*}{$<23 \mathrm{~mm}(\mathrm{n}=50)$} & & $\mathrm{n}=14$ & $\mathrm{n}=17$ & $\mathrm{n}=19$ & \\
\hline & Mean gradient, $\mathrm{mm} \mathrm{Hg}$ & $15.66 \pm 7.32(16.5)$ & $15.00 \pm 4.24(14.5)$ & $17.53 \pm 7.17(16)$ & .49 \\
\hline & Aortic valve area, $\mathrm{cm}^{2}$ & $1.56 \pm 0.15(1.49)$ & $1.56 \pm 0.49(1.38)$ & $1.60 \pm 0.66(1.53)$ & .97 \\
\hline & Aortic valve area index $\mathrm{cm}^{2} / \mathrm{m}^{2}$ & $0.91 \pm 0.35(0.78)$ & $0.87 \pm 0.30(0.76)$ & $0.92 \pm 0.33(0.88)$ & .89 \\
\hline \multirow[t]{4}{*}{$23 \mathrm{~mm}(\mathrm{n}=69)$} & & $\mathrm{n}=22$ & $\mathrm{n}=18$ & $\mathrm{n}=29$ & \\
\hline & Mean gradient, $\mathrm{mm} \mathrm{Hg}$ & $16.32 \pm 5.92(15.5)$ & $11.61 \pm 4.39(10.5)$ & $16.48 \pm 4.07(17)$ & $.002 \S$ \\
\hline & Aortic valve area, $\mathrm{cm}^{2}$ & $1.58 \pm 0.42(1.56)$ & $1.94 \pm 0.29(1.95)$ & $1.74 \pm 0.45(1.67)$ & $.027 \|$ \\
\hline & Aortic valve area index $\mathrm{cm}^{2} / \mathrm{m}^{2}$ & $0.82 \pm 0.26(0.77)$ & $1.04 \pm 0.19(1.06)$ & $0.89 \pm 0.23(0.85)$ & $.013 \pi$ \\
\hline \multirow[t]{4}{*}{$>23 \mathrm{~mm}(\mathrm{n}=98)$} & & $\mathrm{n}=35$ & $\mathrm{n}=33$ & $\mathrm{n}=30$ & \\
\hline & Mean gradient, $\mathrm{mm} \mathrm{Hg}$ & $14.23 \pm 4.22(15)$ & $11.28 \pm 3.80(10)$ & $15.20 \pm 6.00(15)$ & $.004 \#$ \\
\hline & Aortic valve area, $\mathrm{cm}^{2}$ & $2.05 \pm 0.44(2.03)$ & $2.31 \pm 0.50(2.37)$ & $2.21 \pm 0.47(2.16)$ & .082 \\
\hline & Aortic valve area index $\mathrm{cm}^{2} / \mathrm{m}^{2}$ & $0.99 \pm 0.25(0.98)$ & $1.13 \pm 0.28(1.06)$ & $1.04 \pm 0.23(1.06)$ & .099 \\
\hline
\end{tabular}

Values are presented as mean \pm standard deviation (median). *Epic (St Jude, St Paul, Minn). †Magna (Edwards LifeSciences Inc, Irvine, Calif). $\ddagger$ Mitroflow (Sorin Biomedica Spa, Saluggio, Italy). §Mitroflow versus Magna, $P=.004$; Epic versus Magna, $P=.008$; and Mitroflow versus Epic, $P=.99$. $\|$ Mitroflow versus Magna, $P=.26$; Epic versus Magna, $P=.020$; and Mitroflow versus Epic, $P=.353$. .Mitroflow versus Magna, $P=.076$; Epic versus Magna, $P=.011$; and Mitroflow versus Epic, $P=.58$. \#Mitro versus Magna, $P=.004$; Epic versus Magna, $P=.032$; and Mitroflow versus Epic, $P=.69$. 
TABLE E4. One-year echocardiogram data comparison stratified by left ventricular outflow tract (LVOT) size

\begin{tabular}{|c|c|c|c|c|c|}
\hline LVOT size & Echocardiogram at 1 year & Epic* & Magna $†$ & Mitroflow $\ddagger$ & $P$ value \\
\hline \multirow[t]{4}{*}{$\leq 21(\mathrm{n}=57)$} & & $\mathrm{n}=15$ & $\mathrm{n}=21$ & $\mathrm{n}=21$ & \\
\hline & Mean gradient, $\mathrm{mm} \mathrm{Hg}$ & $14.49 \pm 1.42(16)$ & $13.60 \pm 1.23(14)$ & $16.81 \pm 1.20(16)$ & .17 \\
\hline & Aortic valve area, $\mathrm{cm}^{2}$ & $1.63 \pm 0.46(1.61)$ & $1.74 \pm 0.48(1.74)$ & $1.62 \pm 0.62(1.57)$ & .76 \\
\hline & Aortic valve area index $\mathrm{cm}^{2} / \mathrm{m}^{2}$ & $0.95 \pm 0.31(0.90)$ & $0.95 \pm 0.27(0.92)$ & $0.91 \pm 0.32(0.83)$ & .875 \\
\hline \multirow[t]{4}{*}{$22-23(\mathrm{n}=90)$} & & $\mathrm{n}=29$ & $\mathrm{n}=27$ & $\mathrm{n}=34$ & \\
\hline & Mean gradient, $\mathrm{mm} \mathrm{Hg}$ & $17.03 \pm 1.03(16)$ & $12.26 \pm 1.07(12)$ & $16.94 \pm 0.95(15)$ & $.002 \S$ \\
\hline & Aortic valve area, $\mathrm{cm}^{2}$ & $1.64 \pm 0.40(1.53)$ & $2.04 \pm 0.46(2.02)$ & $1.87 \pm 0.50(1.9)$ & $.006 \|$ \\
\hline & Aortic valve area index $\mathrm{cm}^{2} / \mathrm{m}^{2}$ & $0.83 \pm 0.22(0.76)$ & $1.07 \pm 0.28(1.06)$ & $0.93 \pm 0.23(0.93)$ & $.002 \uparrow$ \\
\hline \multirow[t]{4}{*}{$>23(\mathrm{n}=70)$} & & $\mathrm{n}=27$ & $\mathrm{n}=20$ & $\mathrm{n}=23$ & \\
\hline & Mean gradient, $\mathrm{mm} \mathrm{Hg}$ & $13.52 \pm 0.81(12)$ & $10.89 \pm 0.97(11)$ & $14.70 \pm 0.88(15)$ & $.017 \#$ \\
\hline & Aortic valve area, $\mathrm{cm}^{2}$ & $2.08 \pm 0.51(2.12)$ & $2.31 \pm 0.57(2.33)$ & $2.16 \pm 0.53(2.13)$ & .38 \\
\hline & Aortic valve area index $\mathrm{cm}^{2} / \mathrm{m}^{2}$ & $1.01 \pm 0.30(0.98)$ & $1.10 \pm 0.29(1.06)$ & $1.04 \pm 0.24(1.03)$ & .578 \\
\hline
\end{tabular}

TABLE E5. Predictors of left ventricular mass index regression at 1-year follow-up in all patients

\begin{tabular}{|c|c|c|}
\hline Variable & $\begin{array}{c}\text { Univariate } \\
P \text { value }\end{array}$ & $\begin{array}{c}\text { Multivariate } \\
P \text { value }\end{array}$ \\
\hline Age & .754 & .664 \\
\hline Diabetes & .665 & \\
\hline Higher preoperative aortic valve mean gradient & .018 & .336 \\
\hline Higher preoperative left ventricular mass index & $<.001$ & $<.001$ \\
\hline Hypertension & .791 & \\
\hline Implant size No. 19 and $21^{*}$ & .099 & \\
\hline Implant size No. $23^{*}$ & .110 & \\
\hline Male gender & .029 & \\
\hline Prior myocardial infarction & .976 & \\
\hline Severe PPM (AVAi $\left.<0.6 \mathrm{~cm}^{2} / \mathrm{m}^{2}\right)$ & .775 & \\
\hline
\end{tabular}

173.e2 The Journal of Thoracic and Cardiovascular Surgery • January 2015 